\title{
Molecular characterization and protective efficacy of a new conserved hypothetical protein of Eimeria tenella
}

\author{
Huanzhi Zhao ${ }^{1, a}$, Shunhai Zhu ${ }^{1, a}$, Qiping Zhao ${ }^{1}$, Bing Huang ${ }^{1}$, Guiling Liu ${ }^{1,2}$, Zhihang Li ${ }^{1,2}$, Lu Wang ${ }^{1}$, \\ Hui Dong ${ }^{1}$, and Hongyu Han ${ }^{1}$,* \\ ${ }^{1}$ Key Laboratory of Animal Parasitology of Ministry of Agriculture, Shanghai Veterinary Research Institute, CAAS, \\ 200241 Shanghai, PR China \\ 2 College of Life and Environment Sciences, Shanghai Normal University, 200234 Shanghai, PR China
}

Received 2 October 2020, Accepted 15 October 2021, Published online 3 May 2021

\begin{abstract}
Eimeria tenella is an obligate intracellular parasite that actively invades cecal epithelial cells of chickens. This parasite encodes a genome of more than 8000 genes. However, more than $70 \%$ of the gene models for this species are currently annotated as hypothetical proteins. In this study, a conserved hypothetical protein gene of E. tenella, designated EtCHP18905, was cloned and identified, and its immune protective effects were evaluated. The open reading frame of EtCHP18905 was $1053 \mathrm{bp}$ and encoded a protein of 350 amino acids with a molecular weight of $38.7 \mathrm{kDa}$. The recombinant $E t \mathrm{CHP} 18905$ protein (rEtCHP18905) was expressed in E. coli. Using western blot, the recombinant protein was successfully recognized by anti GST-Tag monoclonal antibody and anti-sporozoites protein rabbit serum. Real-time quantitative PCR analysis revealed that the EtCHP18905 mRNA levels were higher in sporozoites than in unsporulated oocysts, sporulated oocysts and second-generation merozoites. Western blot analysis showed that EtCHP18905 protein expression levels were lower in sporozoites than in other stages. Immunofluorescence analysis indicated that the EtCHP18905 protein was located on the surface of sporozoites and second-generation merozoites. Inhibition experiments showed that the ability of sporozoites to invade host cells was significantly decreased after treatment with the anti-rEtCHP18905 polyclonal antibody. Vaccination with $\mathrm{r} E t \mathrm{CHP} 18905$ protein was able to significantly decrease mean lesion scores and oocyst outputs as compared to non-vaccinated controls. The results suggest that the $\mathrm{rEtCHP} 18905$ protein can induce partial immune protection against infection with E. tenella and could be an effective candidate for the development of new vaccines.
\end{abstract}

Key words: Eimeria tenella, Conserved hypothetical protein, Characterization, Vaccine, Chicken coccidiosis.

Résumé - Caractérisation moléculaire et efficacité protectrice d'une nouvelle protéine hypothétique conservée d'Eimeria tenella. Eimeria tenella est un parasite intracellulaire obligatoire qui envahit activement les cellules épithéliales du caecum des poulets. Ce parasite code un génome de plus de 8000 gènes. Cependant, plus de $70 \%$ des modèles de gènes de cette espèce sont actuellement annotés en tant que protéines hypothétiques. Dans cette étude, un gène de protéine hypothétique conservé d'E. tenella, désigné par EtCHP18905, a été cloné et identifié, et ses effets immuno-protecteurs ont été évalués. Le cadre de lecture ouvert d'EtCHP18905 était de 1053 pb et codait pour une protéine de 350 acides aminés avec un poids moléculaire de $38,7 \mathrm{kDa}$. La protéine recombinante EtCHP18905 (rEtCHP18905) a été exprimée dans E. coli. En utilisant le Western blot, la protéine recombinante a été reconnue avec succès par un anticorps monoclonal anti-GST-Tag et un sérum de lapin anti-protéines de sporozoïtes. Une analyse PCR quantitative en temps réel a révélé que les niveaux d'ARNm d'EtCHP18905 étaient plus élevés dans les sporozoïtes que dans les oocystes non sporulés, les oocystes sporulés et les mérozoïtes de deuxième génération. L'analyse par Western blot a montré que les niveaux d'expression de la protéine EtCHP18905 étaient plus faibles dans les sporozoïtes que dans les autres stades. L'analyse par immunofluorescence a indiqué que la protéine EtCHP18905 était localisée à la surface des sporozoïtes et des mérozoïtes de deuxième génération. Des expériences d'inhibition ont montré que la capacité des sporozoïtes à envahir les cellules hôtes était significativement diminuée après le traitement par l'anticorps polyclonal anti-rEtCHP18905. La vaccination avec la protéine rEtCHP18905 a permis de réduire significativement les scores moyens des lésions et les sorties d'oocystes par rapport aux témoins non vaccinés. Les résultats suggèrent que la protéine $\mathrm{r} E t \mathrm{CHP} 18905$ peut induire une protection immunitaire partielle contre l'infection par E. tenella et pourrait être un candidat efficace pour le développement de nouveaux vaccins.

*Corresponding author: hhysh@shvri.ac. cn

${ }^{\mathrm{a}}$ Equal contributors.

This is an Open Access article distributed under the terms of the Creative Commons Attribution License (https://creativecommons.org/licenses/by/4.0), which permits unrestricted use, distribution, and reproduction in any medium, provided the original work is properly cited. 


\section{Introduction}

Avian coccidiosis in the poultry industry is a common disease caused by obligate apicomplexan parasites of the genus Eimeria. At present, coccidiosis has historically been controlled by anticoccidial drugs and live vaccines [34]. However, longterm prophylactic drug usage has promoted drug-resistance. As pressure to reduce drug use in poultry production intensifies industry-wide, novel vaccination strategies are needed. Hence, new strategies such as DNA vaccines and subunit vaccines have received widespread attention. Therefore, it is urgent to find novel immunoprotective antigens.

Eimeria tenella is one of the 7 recognized species of Eimeria that infect chickens. More than 8000 genes of E. tenella have been identified throughout the genome [30]. Significant progress has been achieved over the past few several years identifying E. tenella genes involved in development, differentiation, virulence, and susceptibility to therapy. However, the identification of most genes in the genome remains unknown [2, 30]. The genome of the Houghton strain of E. tenella has been sequenced [30]. The data show that more than $70 \%$ of gene models are currently annotated as hypothetical proteins in E. tenella [2]. These conserved proteins may be important for invasion, development or the E. tenella life cycle. In 2016, Zhai et al. characterized the conserved protein EtCHP559 and studied the function and immunogenicity of EtCHP559 [47]. However, there are many conserved proteins that have neither been studied nor tested for their function.

In the present study, a new conserved hypothetical protein of E. tenella, EtCHP18905 (NCBI reference sequence accession number: XP_013231819), was cloned and recombinant protein GST-EtCHP18905 (rEtCHP18905) was expressed in an Escherichia coli BL21 (DE3) expression system. Polyclonal anti-rEtCHP18905 antibodies were generated and used to localize EtCHP18905 in parasites by immunofluorescence and to assess inhibitory effects in an in vitro assay. The results of the present study indicate that EtCHP18905 may participate in parasite invasion, growth and development.

\section{Materials and methods}

\section{Ethics considerations}

All experiments involving animals were approved by the Institutional Animal Care and Use Committee of Shanghai Veterinary Research Institute, the Chinese Academy of Agricultural Sciences (approval no. SHVRI-SZ-20180106-3), and were conducted in strict compliance following the recommendations outlined in the Guide for the Care and Use of Laboratory Animals.

\section{Animals, parasites and cells}

One-day-old Chinese Pudong yellow broilers were obtained from Shanghai Fuji Biological Technology Co., Ltd and reared in steel cages with a wire floor. Animals were provided with water and feed ad libitum. The birds were placed in a coccidiafree environment. BALB/c mice were purchased from Shanghai Lingchang Biological Technology Co., Ltd. New Zealand rabbits were obtained from Shanghai SLAC Laboratory Animal Co. Ltd.

Eimeria tenella (CAAS21111601) was obtained from the Shanghai Veterinary Research Institute, Chinese Academy of Agricultural Sciences. The parasites were propagated by inoculating 2-week-old chickens, as previously described [40]. Unsporulated (UO) and sporulated oocysts (SO) were obtained and purified using standard procedures [35]. Sporozoites (Spz) were purified in vitro from cleaned SO [28]. Second-generation merozoites (Mrz) were collected from the cecal mucosa scraped from the cecum and the cecal contents of chickens at $115 \mathrm{~h}$ post inoculation (p.i.) and then purified with Percoll [35].

The chicken fibroblast cell line DF-1 (ATCC CRL-12203) was used for in vitro inhibition and immunofluorescence assays [19].

\section{Cloning and sequence analysis of EtCHP18905}

Total RNA was extracted from Spz using TRIzol reagent (TaKaRa, Tokyo, Japan) according to the manufacturer's protocol. Total RNA was extracted from $2.0 \times 10^{7} \mathrm{Spz}$, counted with a hemocytometer using TRIzol reagent (TaKaRa), according to the manufacturer's protocol. RNA samples were resuspended in diethylpyrocarbonate (DEPC) treated water. Complementary DNA (cDNA) was generated from the total RNA with oligo dT primer and SuperScript ${ }^{\mathrm{TM}}$ III Reverse Transcriptase (Invitrogen, Carlsbad, CA, USA).

The complete coding region of EtCHP18905 (GenBank accession number: XP_013231819) was amplified by PCR. EtCHP18905-specific primers (forward primer: 5' - GATGGACCGAGACCGTCGCTC - 3'; reverse primer: $5^{\prime}$ - GCGCTGTGGGGGCTCGGGTCG $-3^{\prime}$ ) were used for the PCR assays with the cDNA of Spz as a template. The amplification products were analyzed by $1 \%$ agarose gel electrophoresis and purified using a QIAquick $^{\circledR}$ Gel Extraction Kit (QIAGEN, Düsseldorf, Germany). The EtCHP18905 fragment was subcloned into the pGEM-T-Easy Vector (Promega, Madison, WI, USA) using T4 DNA ligase to construct a recombinant plasmid pGEM-TEtCHP18905. The recombinant plasmid was subjected to DNA sequencing by Sangon (Shanghai, China).

The full-length cDNA sequence was analyzed using a BLAST search in GenBank (http://www.ncbi.nlm.nih.gov/ BLAST/) and the E. tenella genome database (http://www. genedb.org/Homepage/Etenella). The molecular mass and theoretical isoelectric point were predicted using the ProtParam tool at the ExPASy server (http://web.expasy.org/protparam/). Signal peptides, transmembrane motifs, and protein motifs were predicted using the computational tools SignalP (http://www. cbs.dtu.dk/services/SignalP/), TMHMM (http://www.cbs.dtu. dk/services/TMHMM-2.0/), and Motif Scan (http://hits.isb-sib. ch/cgi-bin/motif_scan), respectively.

\section{Expression and purification of the recombinant EtCHP18905 protein}

A 1053-bp fragment of EtCHP18905 was amplified from the plasmid pGEM-T-EtCHP18905 with the primers: forward primer, 5' - GGAATTCATGGACCGAGACCGTCGCTC - 3'; 
reverse primer, 5' - GCGTCGACGC TGTGGGGGCTCGGGTCG - 3', and ligated into the pGEX-4T-1 vector at the EcoRI and SalI cloning sites (underlined). The recombinant pGEX-4T-EtCHP18905 plasmid was transformed into E. coli BL21 (DE3) cells (Tiangen, Beijing, China). rEtCHP18905 expression in $E$. coli was induced by addition of $0.8 \mathrm{mM}$ Isopropyl- $\beta$-D-1-thiogalactopyranoside (IPTG; Sigma, $\mathrm{St}$ Louis, MO, USA) to the bacteria culture after the $\mathrm{OD}_{600}$ of the culture reached 0.6 at $37{ }^{\circ} \mathrm{C}$. The bacteria were collected by centrifugation at $8000 \times g$ for $10 \mathrm{~min}$ at $4{ }^{\circ} \mathrm{C}$. The bacteria were lysed by sonication and then the bacteria lysates were analyzed by $12 \%$ (w/v) sodium dodecyl sulfate polyacrylamide gel electrophoresis (SDS-PAGE). The rEtCHP18905 protein was purified by cut SDS polyacrylamide gel [3]. The concentration of the sample was determined using a BCA protein assay kit (Beyotime, Haimen, China). The protein was stored at $-20{ }^{\circ} \mathrm{C}$ for later analysis.

\section{Generation of anti-rEtCHP18905 and anti-sporozoite polyclonal serum}

The Spz proteins were prepared using sonication as described by Jiang et al. [19]. To generate polyclonal antibodies, either $50 \mu \mathrm{g}$ or $200 \mu \mathrm{g}$ of the purified $\mathrm{rEtCHP} 18905$ protein or the Spz protein was mixed with Freund's complete adjuvant (Sigma) in a 1:1 mixture and injected into six-week-old BALB/c mice or two-month-old New Zealand white rabbits, respectively. After two weeks, mice and rabbits were immunized with the same dose of antigen emulsified with Freund's incomplete adjuvant (Sigma). And then, the rabbits and mice were re-boosted four times at intervals of 1 week. Finally, the polyclonal antibody serum was collected and stored at $-80{ }^{\circ} \mathrm{C}$ until use. Pre-immune serum was collected from the rabbits' ear vein before immunization for further use as the negative control.

\section{Western blot analysis for rEtCHP18905}

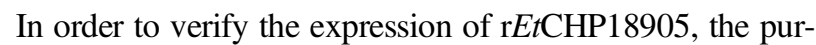
ified $\mathrm{r} E t \mathrm{CHP} 18905$ protein was separated by $12 \%$ SDS-PAGE. All separated proteins were electrically transferred onto polyvinylidene fluoride (PVDF) membrane (Merck Millipore, Billerica, MA, USA). The membranes were blocked in phosphate-buffered saline (PBS) containing 5\% skimmed milk, washed with PBS containing 0.05\% Tween 20 (PBS-T, pH 7.2), and incubated overnight at $4{ }^{\circ} \mathrm{C}$ with the anti GST monoclonal antibody (1:2000) (CoWin Biosciences, Beijing, China) and rabbit anti-Spz proteins of E. tenella serum (1:200), respectively. Secondary antibodies, IRDye ${ }^{\circledR} 800 \mathrm{CW}$ Donkey anti-Mouse IgG and IRDye ${ }^{\circledR} 800 \mathrm{CW}$ Goat anti-Rabbit $\operatorname{IgG}(1: 10,000)$ (LI-COR, Lincoln, NE, USA) were then applied at $37{ }^{\circ} \mathrm{C}$ for $1 \mathrm{~h}$. Naïve rabbit serum (1:200) was used as the negative control. Membranes were scanned with an Odyssey ${ }^{\circledR}$ Infrared Imaging System (LI-COR).

\section{EtCHP18905 transcript levels in different developmental stages of $E$. tenella}

Transcription profiles of EtCHP18905 at different developmental stages of E. tenella (UO, SO, Spz, and Mrz) were determined using real-time quantitative PCR (qPCR). Total RNAs were isolated by TRIzol reagent (Invitrogen) from UO, SO, $\mathrm{Spz}$, and Mrz. RNA preparations were treated with RNase-free DNase I (Invitrogen) to remove DNA contamination. In brief, $1.0 \times 10^{7}$ purified UO or SO were oscillated and broken in $500 \mu \mathrm{L}$ of TRIzol with equal volume of $710-1180 \mu \mathrm{m}$ glass beads (Sigma) for $10 \mathrm{~min}(4000 \mathrm{rpm})$. A total of $2.0 \times 10^{7} \mathrm{Spz}$ or Mrz were lysed in $500 \mu \mathrm{L}$ of TRIzol. Total RNAs were precipitated with isopropanol and washed with $75 \%$ ethanol and then resuspended in DEPC treated water. cDNA was synthesized with SuperScript II reverse transcriptase (Invitrogen) and random primers (Invitrogen). qPCR was performed with SYBR1 Green I dye (Takara) on a StepOne ${ }^{\mathrm{TM}}$ Real-Time PCR System (Thermo Fisher Scientific, Waltham, MA, USA). qPCR primers for EtCHP18905 were: $5^{\prime}$ - TCCCCTCAAGCCCCTCATACAGT - 3' (forward) and 5' - CCAGCACTAAGTCCACTGAACGC - 3' (reverse). A housekeeping gene of E. tenella, $18 \mathrm{~S}$ ribosomal RNA, was used as the reference gene and was amplified using the primers $5^{\prime}-$ TGTAGTGGAGTCTTGGTGATTC - 3' (forward) and $5^{\prime}-$ CCTGCTGCCTTCCTTAGATG - $3^{\prime}$ (reverse). The reactions for each sample were performed in triplicate, and the experiment was repeated three times. The transcription levels were quantified with the $2^{-\Delta \Delta C t}$ method [27].

\section{EtCHP18905 protein expression in four development stages of $E$. tenella}

Total proteins were prepared from four life cycle stages of E. tenella using a commercially available cell-lysis buffer for western blot and immunoprecipitation (Beyotime). Protein concentrations were determined with a BCA protein assay kit (Beyotime). The protein lysate from each sample was separated by SDS-PAGE and transferred to PVDF membrane (Merck Millipore). Membranes were blocked for $2 \mathrm{~h}$ with $5 \%$ (w/v) skimmed milk powder in PBS, followed by incubation with mouse polyclonal anti-rEtCHP18905 (1:100) and mouse monoclonal anti- $\alpha$-tubulin $(1: 5000)$ at $37{ }^{\circ} \mathrm{C}$ for $2 \mathrm{~h}$, respectively. Secondary antibodies, HRP-conjugated Affinipure Goat anti-Mouse IgG (H + L) (1:5000) (Proteintech, Rosemont, IL, USA) were incubated at room temperature for $45 \mathrm{~min}$, and bands were detected using ChemiDoc (Bio-Rad, Hercules, CA, USA). $\alpha$-tubulin (Sigma) was used as an internal reference for protein extracts at each stage. For comparative quantitative protein expression profile analysis, the resulting images were analyzed by Image J (Rawak Software Inc., Stuttgart, Germany) software.

\section{Localization of EtCHP18905 by indirect immunofluorescence}

The location of EtCHP18905 in Spz, Mrz and parasites invaded DF-1 cells were assessed by indirect immunofluorescence assay (IFA) with anti-rEtCHP18905, as previously described [19]. Six-well plates (Corning Inc., Corning NY, USA) precoated with coverslips were seeded with DF-1 cells $\left(2 \times 10^{5}\right.$ cells per well $)$. These cells were sequentially cultured in complete medium (CM, DMEM with $10 \%$ fetal bovine serum and 100 units/mL penicillin/streptomycin) at $37^{\circ} \mathrm{C}$ and $5 \% \mathrm{CO}_{2}$ for $24 \mathrm{~h}$. Freshly cleaned $\mathrm{Spz}\left(6 \times 10^{5}\right.$ parasites per 
well) were added to invade and develop in the DF-1 cells. The coverslips were collected and washed at 2, 48 and $72 \mathrm{~h}$ p.i., respectively. Subsequently, all the coverslips were fixed in $4 \%$ paraformaldehyde for $20 \mathrm{~min}$, permeabilized with $1 \%$ Triton X-100 in PBS for 15 min, and then blocked with $2 \%$ bovine serum albumin in PBS overnight at $4{ }^{\circ} \mathrm{C}$. After washing four times, rabbit anti-rEtCHP18905 polyclonal antibody (1:100 dilution) with PBS was added for incubation at $37{ }^{\circ} \mathrm{C}$ for $2 \mathrm{~h}$. Then the goat anti-rabbit IgG fluorescein isothiocyanate (FITC)-conjugated antibody (1:500 dilution) (Sigma) was added, and the samples were incubated at $37{ }^{\circ} \mathrm{C}$ for $1 \mathrm{~h}$. Nuclei of parasites and cells were stained with $15 \mu \mathrm{g} / \mathrm{mL} 4$, 6-diamidino-2-phenylindole (DAPI) (Beyotime) for $30 \mathrm{~min}$ at room temperature. At the end of each step, all the coverslips were washed three times in PBS. The coverslips were placed on glass slides using $60 \mu \mathrm{L}$ of Fluoromount Aqueous Mounting Medium (Sigma) and observed by a laser scanning confocal microscope (Zeiss LSM800 microscope, Carl Zeiss, Germany). Spz were incubated in PBS or CM for $2 \mathrm{~h}$ at $41{ }^{\circ} \mathrm{C}$, and air dried on coverslips before fixation. Mrz were also incubated in PBS for observation. Spz or Mrz were evenly smeared onto glass coverslips to localize the protein in Spz and Mrz. After air drying, the coverslips were prepared for immunofluorescence using the method described above.

\section{Invasion inhibition assays}

Invasion inhibition assays were performed to investigate whether anti-rEtCHP18905 affects Spz invasion of DF-1 cells [19]. Rabbit IgG against rEtCHP18905 and GST protein were purified using protein $\mathrm{A}+\mathrm{G}$ agarose (Beyotime) and the concentration of IgG was determined by a BCA Protein Assay Kit (Beyotime). DF-1 cells $\left(3 \times 10^{5}\right.$ cells per well $)$ were cultured in flat-bottomed 24-well plates (Corning) in $\mathrm{CM}$ at $37{ }^{\circ} \mathrm{C}$ and $5 \% \mathrm{CO}_{2}$ for $12 \mathrm{~h}$. Freshly cleaned E. tenella $\mathrm{Spz}$ were labeled for 15 min using carboxyfluorescein diacetate succinimidyl ester (CFDA SE) (Invitrogen), according to the manufacturer's protocol. Then, the labeled Spz were incubated with purified rabbit anti-rEtCHP18905 IgG at different concentrations $(100,200$, or $300 \mu \mathrm{g} / \mathrm{mL})$ for $2 \mathrm{~h}$ at $37^{\circ} \mathrm{C}$ and added to infect DF-1 cells at $41{ }^{\circ} \mathrm{C}, 5 \% \mathrm{CO}_{2}$ for $12 \mathrm{~h}$. Naïve rabbit serum IgG (Sigma, USA) and rabbit anti-GST IgG were used as the negative control and GST control. Labeled Spz incubated with no antibody were the positive control. The cells were washed, trypsinized, harvested, and analyzed on a flow cytometer (model Cytomics FC500; Beckman Coulter, Brea, CA, USA). All assays were performed in triplicate. The inhibition rate was calculated based on the invasion rate and the positive control [17].

\section{Immunization experimental design}

Broilers at 7 days of age were randomly divided into four groups and each group included 12 birds. Broilers were inoculated with a subcutaneous injection of $50 \mu \mathrm{g}$ or $100 \mu \mathrm{g}$ of purified $\mathrm{rEtCHP} 18905$ protein emulsified in Montanide ISA 71 adjuvant (Seppic, Puteaux, France) in a 3:7 mixture [18]. The challenged and unchallenged control birds were immunized with PBS emulsified in Montanide ISA 71 adjuvant. A booster immunization was given one week later with the same amount of components as the first immunization. Subsequently, 7 days after the last immunization, $1 \times 10^{4} \mathrm{SO}$ of E. tenella were given to all the birds except for the unchallenged control birds. Unchallenged control chickens were given PBS orally.

\section{Evaluation of immune protection}

The efficacy of immunization was evaluated by the average body weight gain, mean lesion scores, fecal oocyst output, and percentage reduction of oocyst excretion. Body weight was measured on days 0 and 8 post challenge. Fecal samples were collected daily from days 6 to 8 post challenge. Oocysts per gram of fecal sample were counted using a McMaster chamber [9]. The percentage reduction of oocyst excretion was calculated by the formula: (number of oocysts from the challenged-unvaccinated group - number of oocysts from the challenged- vaccinated group)/number of oocysts from the challenged-unvaccinated group $\times 100 \%$ [31]. The ceca of each group were collected separately. Intestinal lesions were scored according to the method of Johnson and Reid [20].

\section{Preparation of the serum}

The blood of broilers in each group was collected on day 8 post challenge. For the serum IgG, cytokines, sCD4 and sCD8 determination, the sera were separated from isolated blood samples. In brief, the blood samples were incubated at $37{ }^{\circ} \mathrm{C}$ for $1 \mathrm{~h}$, and centrifuged at $1000 \times g$ for $5 \mathrm{~min}$ at $4{ }^{\circ} \mathrm{C}$ to separate the serum.

\section{Determination of serum antibody levels}

The serum IgG against rEtCHP18905 levels were detected by ELISA at day 8 post challenge, as described previously [24]. Briefly, 96-well microtiter plates (Corning) were coated with

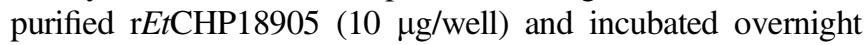
at $4{ }^{\circ} \mathrm{C}$. After three washes with PBS-T, the plate was blocked with PBS containing $1 \%$ BSA for $2 \mathrm{~h}$ at $37^{\circ} \mathrm{C}$, and then the plate was washed with PBS-T. The plates were incubated with the serum samples diluted 1:25 in PBS (50 $\mu \mathrm{L} /$ well) for $2 \mathrm{~h}$ at $37{ }^{\circ} \mathrm{C}$. After washing five times with PBS-T, the secondary antibodies of HRP-donkey-anti-chicken $\mathrm{IgG}$ antibody (50 $\mu \mathrm{L} /$ well) (Sigma) (1:5,000 dilution) was added and incubated for $2 \mathrm{~h}$ at $37^{\circ} \mathrm{C}$. The plates were washed five times with PBS-T and developed with 3,3',5,5'-tetramethylbenzidine. Optical densities at $450 \mathrm{~nm}$ (OD450) were determined on a microplate spectrophotometer. All assays were performed in triplicate.

\section{Determination of cytokine, SCD4 and SCD8 levels}

The immune stimulation effect of $\mathrm{rEtCHP} 18905$ protein on broilers was measured by ELISA at day 8 post challenge, as previously described $[6,22,24,25]$. The levels of cytokines, soluble cluster of differentiation 4 (sCD4), soluble cluster of differentiation 8 (sCD8), interferon- $\gamma$ (IFN- $\gamma$ ), interleukin-10 (IL-10), interleukin-17 (IL-17), and transforming growth factor 


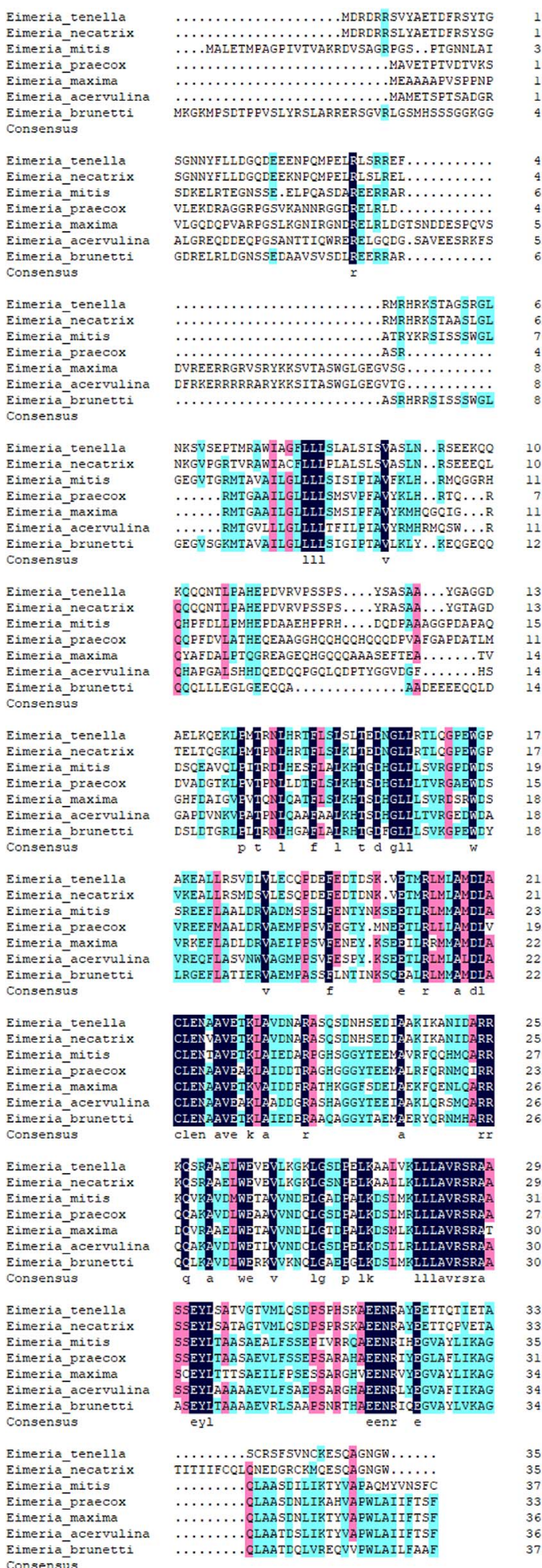

Figure 1. Multiple alignment analysis of EtCHP18905 with other Eimeria proteins. DNAMAN was used to analyze the deduced protein sequences. The identical amino acids are listed at the bottom. NCBI reference sequence accession numbers: Eimeria tenella, XP_013231819, Eimeria necatrix, XP_013438465, Eimeria mitis, XP_013355934, Eimeria maxima, XP_013336337, Eimeria acervulina, XP_013251133; GenBank accession numbers: Eimeria praecox, CDI76926, Eimeria brunetti, CDJ52365.
ATGGACCGAGACCGTCGCTCCGTTTACGCCGAAACTGACTTCAGGTCATACACTGGCAGTGGCAACAATTAT \begin{tabular}{llllllllllllllllllllllll}
$M$ & $D$ & $R$ & $D$ & $R$ & $R$ & $S$ & $V$ & $Y$ & $A$ & $E$ & $T$ & $D$ & $F$ & $R$ & $S$ & $Y$ & $T$ & $G$ & $S$ & $G$ & $N$ & $N$ & $Y$ \\
\hline
\end{tabular}

73 TTCCTCTTGGATGGTCAGGATGAAGAGGAGAATCCTCAGATGCCAGAACTGCGACTGTCGCGGCGGGAATTT

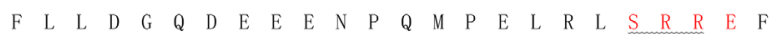

145 CGGATGAGGCACAGGAAATCGACAGCTGGTTCGCGGGGACTCAACAAGAGTGTCTCGGAGCCTACAATGAGG $\begin{array}{llllllllllllllllllllllll}R & M & R & H & R & K & S & T & A & G & S & R & G & L & N & K & S & V & S & E & P & T & M & R\end{array}$

217 GCGTGGATTGCTGGTTTTCTGCTTTTGTCCTTGGCATTATCCATATCTGTGGCTAGCCTTAATAGAAGCGAG A

289 GAAAAGCAGCAGAAGCAACAGCAAAACACTTTGCCCGCTCACGAACCGGATGTCCGAGTCCCCTCAAGCCCC $\begin{array}{llllllllllllllllllllllll}E & K & Q & Q & K & Q & Q & Q & N & T & L & P & A & H & E & P & D & V & R & V & P & S & S & P\end{array}$

361 TCATACAGTGCATCAGCAGCTTACGGTGCTGGAGGAGATGCAGAGTTGAAGCAAGAGAAACTGCCTATGACA $\begin{array}{llllllllllllllllllllllll}S & Y & S & A & S & A & A & Y & G & A & G & G & D & A & E & L & K & Q & E & K & L & P & M & T\end{array}$

433 CGGAACCTCCACCGCACCTTCCTGTCTCTCAGCCTCACAGAGGACAACGGGCTGCTGCGAACCCTACAGGGC $\begin{array}{llllllllllllllllllllllll}R & N & L & H & R & T & F & L & S & L & S & L & T & E & D & N & G & L & L & R & T & L & Q & G\end{array}$

505 CCCGAATGGGGACCAGCAAAGGAAGCGCTGCTGCGTTCAGTGGACTTAGTGCTGGAGTGTCAGCCGGATGAG

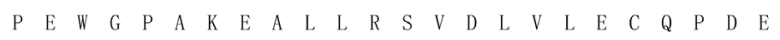

577 TTTGAAGATACAGACAGTAAAGTGGAGACTATGCGGCTGATGCTTGCGATGGACTTGGCGTGTCTTGAAAAC

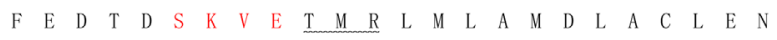

649 GCAGCGGTGGAGACCAAGCTGGCTGTAGACAATGCGAGGGCCAGTCAGTCGGATAATCACAGCGAAGACATA

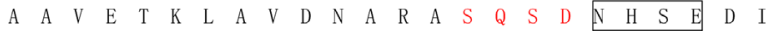

721 GCTGCAAAAATAAAAGCGAACATCGACGCGAGGAGAAAACAGTCTAGAGCAGCCGAGCTGTGGGAGGTAGAG $\begin{array}{llllllllllllllllllllllll}A & A & K & I & K & A & N & I & D & A & R & R & K & Q & S & R & A & A & E & L & W & E & V & E\end{array}$

793 GTGCTGAAAGGCAAGCTGGGATCCGATCCCGAACTCAAAGCAGCGCTTGTCAAGTTGTTGCTGGCCGTCCGC

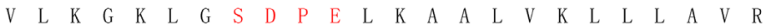

865 AGCAGAGCAGCATCAAGTGAGTACCTCAGTGCTACTGTTGGCACTGTGATGCTGCAGAGCGACCCGAGCCCC

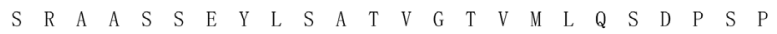
937 CACAGCAAGGCTGAGGAGAACAGGGCTTATGAAGAAACTACTCAAACAATCGAAACTGCATCGTGCCGATCA $\begin{array}{llllllllllllllllllllllll}H & S & K & A & E & E & N & R & A & Y & E & E & T & T & Q & T & I & E & T & A & S & C & R & S\end{array}$ 1009 TTTTCTGTCAACTGCAAGGAGAGCCAAGCTGGCAACGGCTGGTAA

$\begin{array}{llllllllllllllllllllllll}F & S & V & N & C & K & E & S & Q & A & G & N & G & W & *\end{array}$

Figure 2. Bioinformatic analysis of EtCHP18905. The stop codon is indicated with an asterisk. N-myristoylation sites are double underlined. The transmembrane domain is shaded yellow with black lettering. N-glycosylation sites are surrounded by a black box. cAMP- and cGMP-dependent protein kinase phosphorylation sites are shaded black with white lettering. Tyrosine kinase phosphorylation site is shaded grey with black lettering. Casein kinase II phosphorylation sites are indicated with red lettering. Protein kinase $\mathrm{C}$ phosphorylation sites are underlined by a wavy line.

(TGF- $\beta 1$ ) were determined with "Chicken Cytokine ELISA Quantization Kits" (CUSABIO, Wuhan, China), according to the manufacturer's instructions.

\section{Statistical analysis}

SPSS version 22 (SPSS, Chicago, IL, USA) was used to analyze body weight gain, mean lesion scores, and fecal oocyst output and oocyst reduction ratio. GraphPad Prism version 6.0 (GraphPad, La Jolla, CA, USA) was used to analyze real-time quantitative PCR (qPCR), invasion inhibition, and antibody and cytokine levels. Differences among groups were analyzed by one-way analysis of variance (ANOVA) and Duncan's multiple range test $(p<0.05$ was considered significantly different). The lesion scores were compared by the nonparametric KruskalWallis test.

\section{Results}

\section{Characterization of the EtCHP18905 sequence}

By analysis of the sequence, the open reading frame (ORF) was $1053 \mathrm{bp}$ and found to encode a protein of 350 amino acids with a predicted molecular mass of $38.7 \mathrm{kDa}$. Based on BLASTp analysis, the sequence obtained shared $100 \%, 84.68 \%, 52.48 \%$, 
A

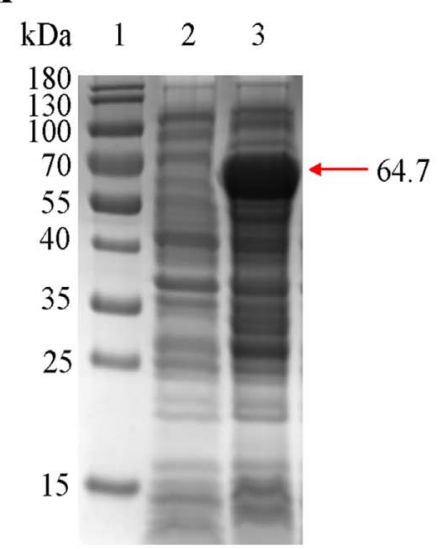

B

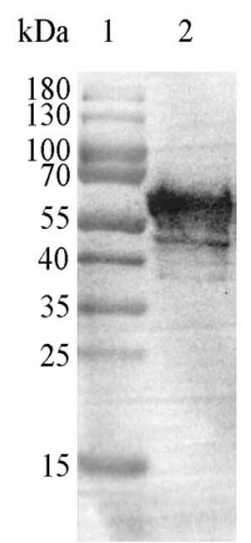

$\mathrm{C}$

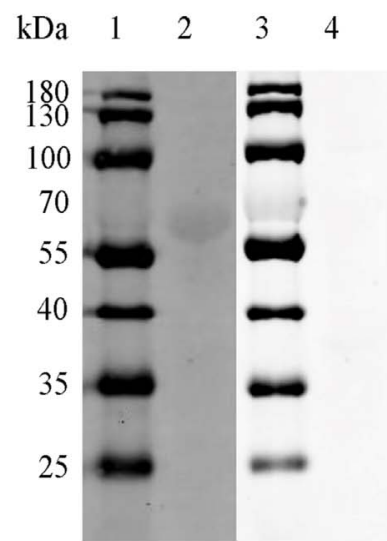

Figure 3. Expression and purification of rEtCHP18905. (A) SDS-PAGE analysis of the 5rEtCHP18905. Lanes 1, protein marker; 2, negative control (not induced with IPTG); 3, the rEtCHP18905 protein with the GST-tag protein of the vector (induced with IPTG for 6 h). (B) Western blot analysis of purified $\mathrm{rEtCHP18905}$ protein. Lane 2, protein recognized by an anti GST-Tag monoclonal antibody. (C) Western blot analysis of purified rEtCHP18905 protein. Lane 2, protein recognized by rabbit sera against sporozoite, lane 4 incubated with naïve rabbit serum.

$40.53 \%, 44.53 \%, 39.10 \%, 41.83 \%$ and $47.74 \%$ amino acid homology with conserved hypothetical protein (CHP) from E. tenella (NCBI reference sequence accession number: XP_013231819) and Eimeria necatrix (XP_013438465), Eimeria mitis (XP_013355934), Eimeria maxima (XP_013336337), Eimeria acervulina (XP_013251133), Eimeria praecox (CDI76926), and Eimeria brunetti (CDJ52365) (Fig. 1), respectively. Analysis of the amino acid sequence showed that a transmembrane domain (amino acid sequence 73-92) was found in the deduced protein, but no signal peptide was detected. Structural module and conservative structure predictions indicated that the protein contains seven casein kinase II phosphorylation sites, four protein kinase $\mathrm{C}$ sites, three $\mathrm{N}$-glycosylation sites, three $\mathrm{N}$-myristoylation sites, two cAMP and cGMP-dependent protein kinases phosphorylation sites and a tyrosine kinase phosphorylation site (Fig. 2).

\section{Expression and purification of recombinant EtCHP18905}

SDS-PAGE analysis showed that the recombinant protein was expressed in E. coli BL21 cells successfully and found mainly in the precipitate. After purification by cut SDS polyacrylamide gel, the expected protein band of $64.7 \mathrm{kDa}$ (including with GST tag) (Fig. 3A) was observed in the SDS-acrylamide gel. Western blot analysis indicated that the recombinant protein was recognized by the anti-GST monoclonal antibody (Fig. 3B) and rabbit sera against Spz of E. tenella (Fig. 3C, lane 2). Normal rabbit serum failed to detect any protein of the expected molecular weight of $\mathrm{r} E t \mathrm{CHP} 18905$ (Fig. 3C, lane 4).

\section{Transcription of EtCHP18905 at different developmental stages of $E$. tenella}

qPCR results showed that the levels of EtCHP18905 mRNA in UO, SO and Mrz were similar $(p>0.05)$, which were significantly lower than those in the Spz $(p<0.05)$ (Fig. 4).

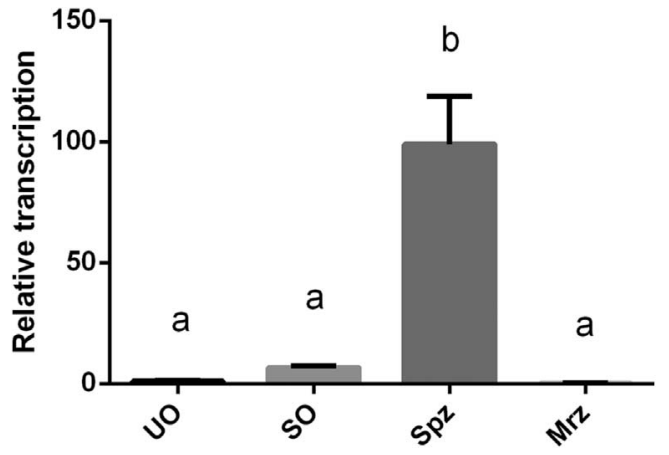

Figure 4. Transcription levels of EtCHP18905 in different developmental stages of E. tenella. UO, unsporulated oocysts; SO, sporulated oocysts; Spz, sporozoites; Mrz, merozoites. Bars with different letters indicate significantly different expression levels $(p<0.05)$ and the error bars indicate standard deviations.

\section{EtCHP18905 protein expression level in E. tenella}

Western blot analysis results indicated that EtCHP18905 expression levels were higher in the UO and SO than Mrz and Spz stages, and EtCHP18905 expression levels were lowest in the Spz stage (Fig. 5).

\section{Localization of EtCHP18905 during in vitro infection}

Indirect immunofluorescence results showed that in $\mathrm{Spz}$ incubated with PBS, EtCHP18905 was distributed on the surface of Spz (Fig. 6A). EtCHP18905 uniformly distributed throughout the cytoplasm in whole $\mathrm{Spz}$ after incubation in CM (Fig. 6B). After Spz were added to DF-1 cells for $2 \mathrm{~h}$ and $48 \mathrm{~h}, E t \mathrm{CHP} 18905$ was concentrated on the surface of Spz (Figs. 6C and 6D). After infection for 72 h, EtCHP18905 was evenly distributed in most areas of the parasite (Fig. 6E). Moreover, EtCHP18905 was primarily located on the surface of Mrz (Fig. 6F). 
A

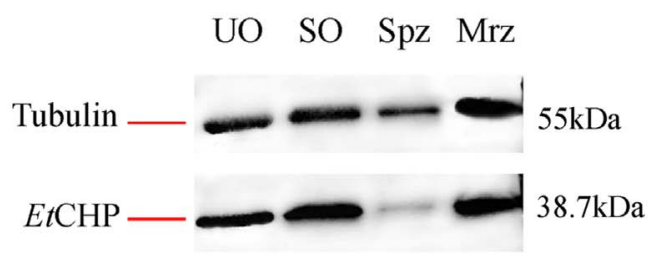

B

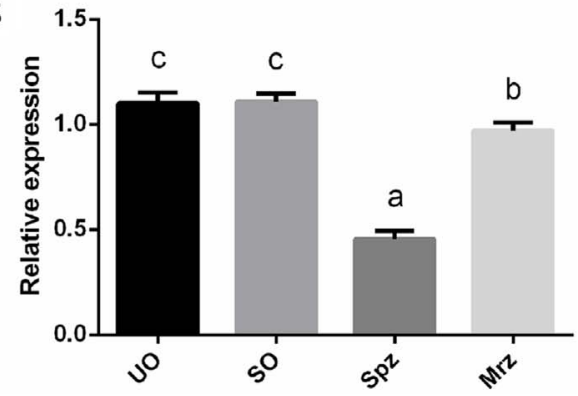

Figure 5. Expression levels of EtCHP18905 in different developmental stages of E. tenella. (A) Western blot of the internal reference tubulin and $E t$ CHP18905 protein. (B) Relative expression levels of the EtCHP18905 protein. Bars with different letters indicate significantly different expression levels $(p<0.05)$ and the error bars indicate standard deviations.
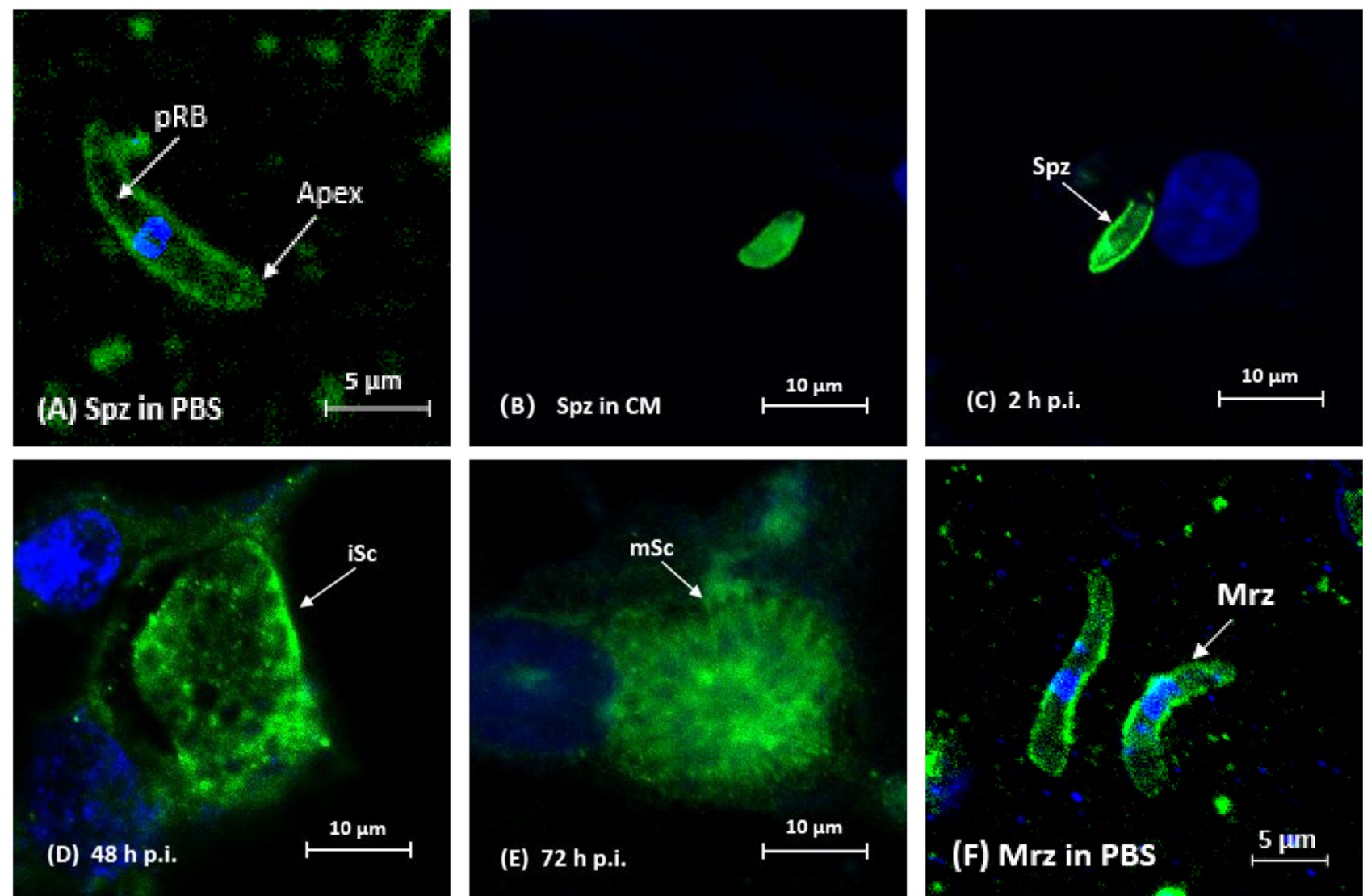

Figure 6. Localization of $E t \mathrm{CHP} 18905$ in infected DF-1 cells by indirect immunofluorescence. Parasites incubated with anti-rEtCHP18905, stained with FITC (green)-conjugated secondary antibodies, and counterstained with DAPI (blue). Infected DF-1 cells were collected at indicated time points post-infection. (A) Sporozoites (Spz) in PBS, pRB, posterior refractile body; (B) Spz in complete medium. Infected DF-1 cells were collected at the indicated time points post-infection (pi); (C) 2 hours pi (hpi); (D) immature schizonts (iSC) 48 hpi; (E) mature schizonts (mSC) 72 hpi; (F) merozoites (Mrz) in PBS.

\section{In vitro invasion inhibition assay}

In vitro invasion inhibition assay results showed that the inhibition rate was $28 \%$ at an antibody concentration of $300 \mu \mathrm{g} / \mathrm{mL}$ (Fig. 7). Compared with naïve rabbit $\operatorname{IgG}$ and GST control groups, the inhibition effect after pretreatment with anti-rEtCHP18905 IgG was significant $(p<0.01)$. In contrast, naïve rabbit sera IgG and GST control groups did not have a significant effect on invasion by E. tenella Spz.

\section{Protective efficacy of vaccination on E. tenella challenge}

Body weight gain, cecal lesion scores, oocyst output and the percentage reduction of oocyst excretion are summarized in Table 1. The results showed that non-immunized challenged control groups exhibited significantly reduced weight gain compared with all immunized groups and the unchallenged control group chickens $(p<0.05)$ after challenge. The cecal lesion 


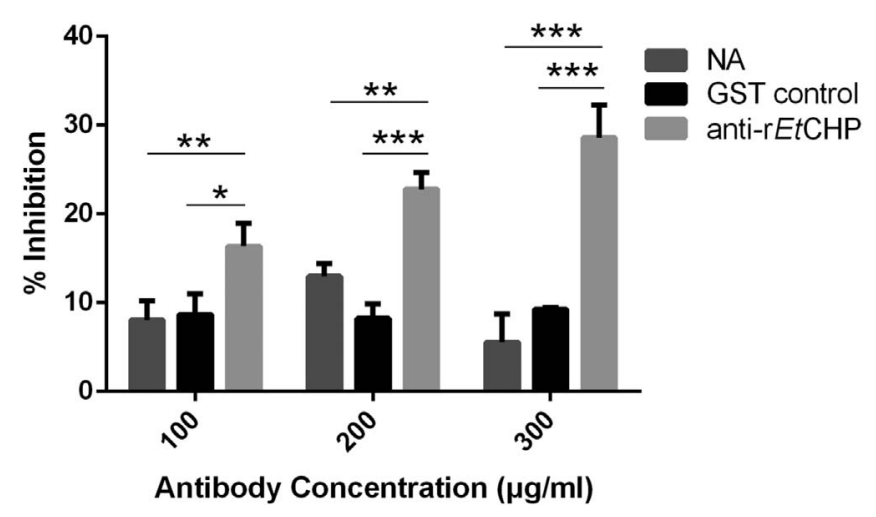

Figure 7. Inhibition of sporozoite invasion in vitro by antirEtCHP18905. Anti-rEtCHP18905, rabbit anti-rEtCHP18905 IgG; NA, naïve rabbit sera IgG; GST control, rabbit anti-GST IgG. The symbol “*” represents $p<0.05$, “**" represents $p<0.01$, and “***" represents $p<0.001$ for comparison of treatment with anti$\mathrm{rEtCHP} 18905$ and naïve rabbit sera IgG and anti-GST IgG at the same concentration. The error bars indicate the standard deviation. All assays were performed in triplicate.

scores of chickens immunized with $\mathrm{rEtCHP18905}$ were significantly lower than those of the challenged control. The oocyst output was reduced after immunization with rEtCHP18905. Chickens immunized with rEtCHP18905 presented significantly higher percentage reduction of oocyst excretion compared with the challenged controls $(p<0.05)$.

\section{IgG titers and cytokine, sCD4 and sCD8 concentrations in sera of immunized chickens}

The results in Figure 8A show that serum from chickens immunized with $\mathrm{rEtCHP18905}$ had significantly higher levels of $\operatorname{IgG}$ antibody $(p<0.001)$ compared with the challenged control group. sCD4 levels in chickens from the two immunized groups were not significantly higher $(p>0.05)$ than the challenged control group, but were significantly lower than the unchallenged group (Fig. 8B). No significant differences $(p>0.05)$ of $\mathrm{sCD} 8$ and IL-10 were observed between the immunized and unimmunized-challenged group (Figs. 8C and $8 \mathrm{E})$. The IFN- $\gamma$ levels in the $100 \mu \mathrm{g} \mathrm{rEtCHP18905-immunized}$ group were higher but not significantly than challenged control (Fig. 8D). IL-17 100- $\mu$ g-immunized group and TGF- $\beta 1$ in chickens from the two immunized groups all showed significantly higher levels $(p<0.05)$ compared with the unchallenged group (Figs. $8 \mathrm{~F}$ and $8 \mathrm{G}$ ).

\section{Discussion}

In the present report, a new gene of conserved hypothetical protein from E. tenella was cloned and characterized. The 1053 bp ORF was shown to encode a 350 amino acid polypeptide of $\sim 38.7 \mathrm{kDa}$. Sequence analysis showed that the protein had no signal peptide, and amino acids 73-92 formed a transmembrane region. Given this observation, it is speculated that the protein is anchored to the membrane. Bioinformatics analysis predicted that the protein contains seven tyrosine kinase phosphorylation sites, four protein kinase
C sites, three $\mathrm{N}$-glycosylation sites, three $\mathrm{N}$-myristoylation sites, two cAMP and cGMP-dependent proteins kinase phosphorylation sites, and one tyrosine kinase phosphorylation site. These sites and structures indicate that the function of this protein may be regulated by post-translational modifications. The BLASTp results showed that the deduced amino acid sequence of EtCHP18905 was $100 \%$ homologous to the E. tenella conserved hypothetical protein (NCBI reference sequence accession number: XP_013231819, GeneID: ETH_00018905) and $84 \%$ homologous to the E. necatrix conserved hypothetical protein (NCBI reference sequence accession number: XP_013438465). These results indicate that CHP in E. tenella and CHP in E. necatrix have high homology. Eimeria tenella and E. necatrix are the most pathogenic species among the species represented in the genus Eimeria, which cause severe tissue damage to the host intestine [33]. In addition, the $E t C H P 18905$ protein is a putative interacting protein of the EtCDPK3 that we screened by a yeast two-hybrid system. In this series of experiments, although we were not able to show an interaction between EtCDPK3 and EtCHP using GST pull-down and Co-IP methods (data not shown), we speculated that this protein may be involved in invasion of host cells and development of E. tenella.

The mRNA and protein levels of EtCHP18905 were examined in four different developmental stages. According to qPCR, the EtCHP18905 gene was most prominent in Spz of E. tenella, and only weakly detected in UO and Mrz. These results showed that the EtCHP18905 gene was transcribed predominantly at a distinct phase of the E. tenella life cycle. However, western blot showed that protein levels were weakest for EtCHP18905 in SO. A previous study revealed that the ratios between protein and mRNA are mainly determined by translation and protein degradation in a cell [8]. However, the two processes of translation and protein degradation are highly regulated at the overall and gene-specific level [8]. Their study revealed that $15-70 \%$ of the variation is explained by posttranscriptional and posttranslation regulation and by measurement errors [5]. Hence, this may explain why the mRNA level of EtCHP18905 is inconsistent with the protein level. However, the specific reasons for this difference need to be investigated further.

The localization of the EtCHP18905 protein in different developmental stages of parasite development was also investigated using an antibody raised against the rEtCHP18905. Indirect immunofluorescence showed that EtCHP18905 was located on the membrane of E. tenella Spz and Mrz stages, which was consistent with the transmembrane protein structure data indicating that the protein was anchored to the membrane. Moreover, immunofluorescence showed that staining was stronger in the Mrz stage. Western blot analysis showed that the expression levels of EtCHP18905 in the Mrz stage was higher than in the Spz stage. However, this result was inconsistent with the results at the transcription level. This may be due to posttranslational modifications [29]. Results from previous studies have suggested that mRNA abundance is a poor indicator of the levels of the corresponding protein [1, 10, 13]. Furthermore, the expression of EtCHP18905 increased after the Spz invaded DF-1 cells for $2 \mathrm{~h}$. Thus, this protein might function in Spz invasion or schizonts evolution. The results of the in vitro experiments confirm this. In vitro invasion inhibition assays using 
Table 1. Protective effect of $\mathrm{r} E t \mathrm{CHP}$ protein on E. tenella infection.

\begin{tabular}{|c|c|c|c|c|}
\hline Group & $\begin{array}{c}\text { Average body } \\
\text { weight gains (g) }\end{array}$ & Mean lesion scores & $\begin{array}{l}\text { Oocyst shedding } \\
\text { per bird }\left(\times 10^{7}\right)\end{array}$ & $\begin{array}{c}\text { Percentage reduction } \\
\text { of oocyst excretion }(\%)\end{array}$ \\
\hline Unchallenged control & $258.62 \pm 70.26^{\mathrm{c}}$ & $0.00 \pm 0.00^{\mathrm{a}}$ & $0.00 \pm 0.00^{\mathrm{a}}$ & $100^{\mathrm{d}}$ \\
\hline Challenged control & $180.87 \pm 45.38^{\mathrm{a}}$ & $3.20 \pm 0.83^{c}$ & $4.43 \pm 0.99^{c}$ & $0.00^{\mathrm{a}}$ \\
\hline $\mathrm{r} E t \mathrm{CHP}-50 \mu \mathrm{g}$ & $226.25 \pm 24.47^{b}$ & $1.75 \pm 0.95^{b}$ & $2.10 \pm 0.88^{b}$ & $54.07 \pm 11.76^{\mathrm{c}}$ \\
\hline $\mathrm{r} E t \mathrm{CHP}-100 \mu \mathrm{g}$ & $235.25 \pm 23.44^{b c}$ & $1.20 \pm 0.44^{b}$ & $3.26 \pm 2.47^{\mathrm{bc}}$ & $31.99 \pm 29.35^{\mathrm{b}}$ \\
\hline
\end{tabular}

${ }^{\mathrm{a}-\mathrm{d}}$ Values with different letters in the same column are significantly different $(P<0.05)$ according to the ANOVA Duncan test.

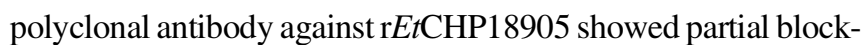
age of the invasion of Spz into cells. Inhibition of sporozoites was modest at $28 \%$, at antibody concentrations of $300 \mu \mathrm{g} / \mathrm{mL}$. Likewise, the rate of invasion inhibition increased with the increase of anti-rEtCHP18905 IgG concentration. Previous studies have shown that polyclonal antibodies can significantly inhibit Spz invading DF-1 cells [7, 11, 19, 48]. In 2016, Zhai et al. found that rabbit antiserum against rEtCHP559 can block invasion of host cells by Spz [47]. The above results suggest that EtCHP18905 is related to invasion. This new antigen might be useful for identification of novel vaccine targets, thus improving the knowledge of immunogenic proteins in E. tenella.

In previous research, many DNA and recombinant protein vaccines have been reported to induce immuno-protection to live parasite challenge [18, 43, 44]. In the present study, following infection challenge, the body weight gain of nonimmunized chickens was reduced significantly compared with immunized chickens. Moreover, chickens immunized with rEtCHP18905 had significantly lower lesion scores and fecal oocyst output compared to non-immunized birds. Previous studies of Eimeria spp. proteins have shown that a similar effect can be produced after immunization with recombinant protein or recombinant plasmid $[25,26]$. The data presented here showed that immunization with rEtCHP18905 could produce partial protection against live E. tenella infection. However, the difference of oocysts output between challenged control groups and the two immunized groups may be under reality. This was probably due to widespread tissue damage and severe hemorrhage that prevents a large number of merozoites from reinfecting intestinal epithelial cells, resulting in a decrease in average oocyst production [12]. It, therefore, appears likely that the differences in lesion score and oocyst output can be caused by merozoite loss [12]. Furthermore, the decrease in oocyst output is not as high as in previous studies [16, 47]. Thus, the effect of $\mathrm{rEtCHP} 18905$ in reducing oocyst shedding should be researched further.

Humoral immunity in the immune response against coccidiosis is usually considered to play a minor role [45]. However, as early as 2008, Constantinoiu et al. pointed out that humoral immunity may also contribute to protective immune responses [4]. Their study revealed that chicken infected with an attenuated strain of E. tenella mount an antibody response to all lifecycle stages. High levels of antibodies against Spz and Mrz were detected in infected chickens inoculated with SO of E. tenella [4]. Moreover, in 1994, Smith also found that antibodies could inhibit parasite development and provide passive immune protection [36]. They found that there was an excellent correlation between antibody titer and protection. Oral infection of hens with E. maxima oocysts caused production of antibodies which were passed into the egg yolk and subsequently to hatchlings. The total number of oocysts excreted in the feces of chicks from eggs has decreased after infection with E. maxima oocysts [36]. Huang et al. [16] reported that birds immunized with the E. maxima rMIC7 protein and pVAX1-MIC7 exhibited higher IgG concentrations than the PBS and pVAX1 controls. In the present study, the IgG concentrations of the $\mathrm{rEtCHP18905-immunized} \mathrm{chickens}$ were significantly higher than the negative controls. These findings confirmed that in rEtCHP18905-immunized chickens, certain humoral immune responses were induced.

Cell-mediated immunity plays a major role against coccidiosis [39]. The concentration of soluble sCD4 and sCD8 in serum is consistent with the number of CD4+ and CD8+ lymphocytes that produce them [41, 46]. Previous studies reported that levels of $\mathrm{sCD} 4$ and $\mathrm{sCD} 8$ were higher in experimental groups immunized with $\mathrm{rEmSAG}$ and $\mathrm{rEmMIC7}$ compared with the control $[16,26]$. However, the results presented here showed that serum sCD4 and sCD8 were not significantly different in immunized chickens compared to non-immunized controls. This suggests that $\mathrm{rEtCHP18905}$ could not stimulate the recruitment of T-cell subpopulations. IFN- $\gamma$ is reported to be related to protective immune responses to avian coccidiosis [23]. A previous study found that IFN- $\gamma$ concentrations were higher in EmMIC7-vaccinated birds [16]. However, $\mathrm{rEtCHP18905}$ increased the serum concentrations of IFN- $\gamma$ but not significantly compared to the control group. Nevertheless, the relative importance of each cytokine type in inducing immune challenge could not be inferred from these data.

One of the Th2-type cytokines, IL-10 and IL-17 are also involved in immune response to coccidial challenge. IL-10 has been shown to be crucial for control of Eimeria infections [32]. Wu et al. observed that serum IL-10 levels increased on day 5 after infection with E. tenella [42]. However, in this study, there was no significant level of IL-10 detected in groups immunized with rEtCHP18905. Previous reports have shown that the immunization of animals with DNA vaccines produced higher levels of IL-17 [14, 37]. In previous vaccination trials, IL-17 concentrations in the vaccinated groups were significantly higher than those of the unvaccinated groups [16, 26]. In the current study, the concentrations of IL-17 in the immunized groups were also significantly higher than the non-immunized groups. The previous study, and our data, together confirm that IL-17 might be associated with protective immunity to coccidiosis. However, the specific functions of IL-10 and IL-17 in the immunity to coccidiosis requires further investigation.

The Treg-type cytokines TGF- $\beta$, produced by Treg cells, have been shown to regulate immunosuppression mechanisms 

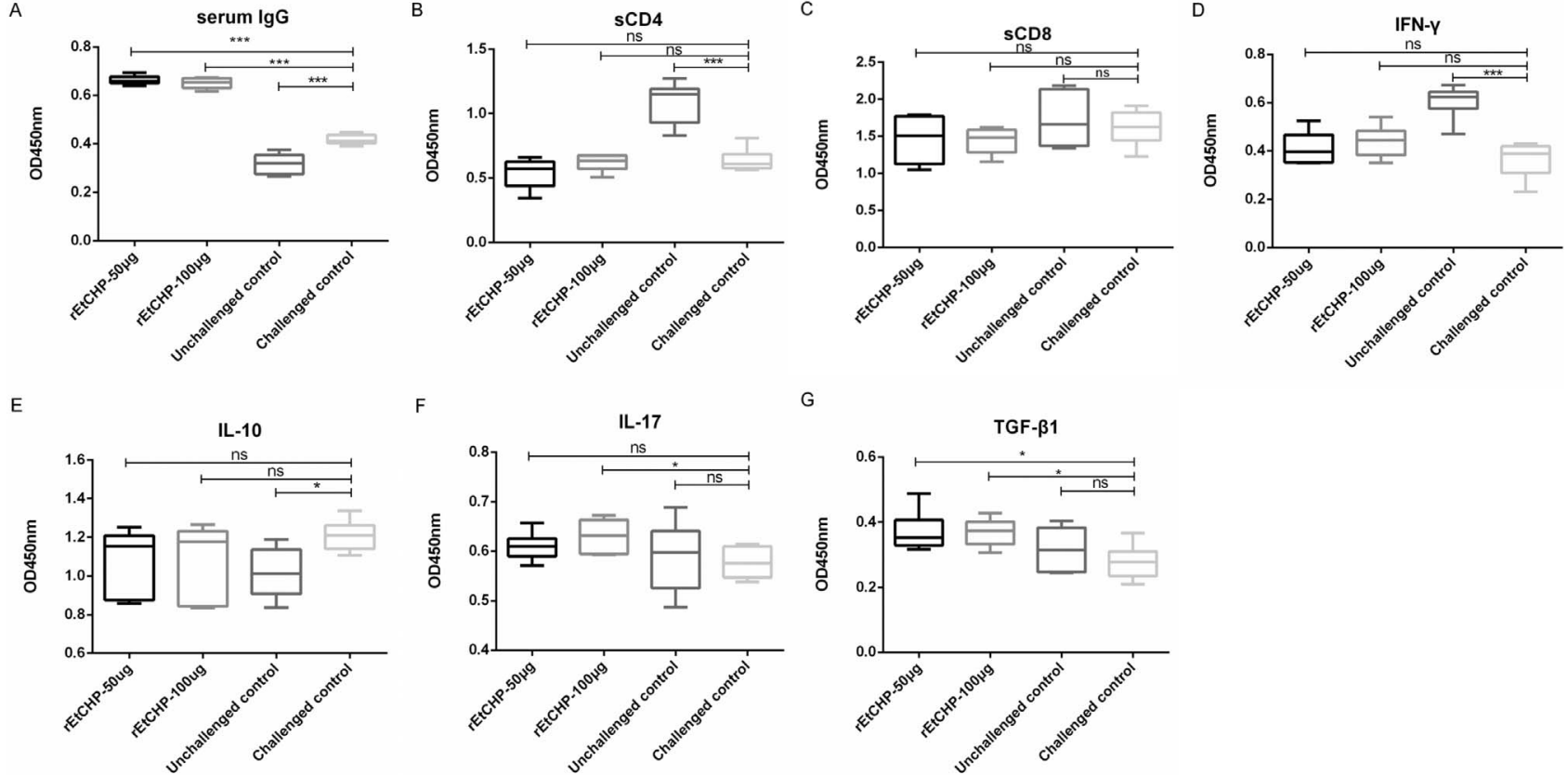

Figure 8. Levels of IgG (A), sCD4 (B), sCD8 (C), cytokines IFN- $\gamma$ (D), IL-10 (E), IL-17 (F) and TGF- $\beta 1$ (G) in chicken sera were measured

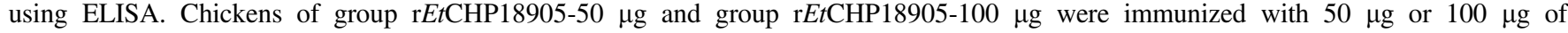
$\mathrm{r} E t \mathrm{CHP} 18905$ protein, respectively. Challenged and unchallenged groups were immunized with PBS and served as controls. The IgG titers and the concentrations of sCD4, sCD8, and cytokines are expressed as Min to Max. $\left({ }^{*} p<0.05,{ }^{*} p<0.01, * * * p<0.001\right.$; ns, $\left.p>0.05\right)$.

[21]. Two earlier reports showed that TGF- $\beta$ was significantly higher in chickens immunized with recombinant EbAMA1 $[38,49]$. The same result was demonstrated by Liu et al. [26]. Likewise, in the present study, the levels of the TGF- $\beta 1$ in the rEtCHP18905-immunized groups were significantly higher than the non-immunized group. These findings together confirm that TGF- $\beta 1$ may function in coccidiosis-induced immune pathways.

In summary, Th2-type cytokines can down-regulate the expression levels of Th1-type cytokines and regulate the immune response [15]. In the present study, IL-17 and TGF- $\beta 1$ levels increased following immunization. In contrast, sCD4, sCD8 and IL-10 did not increase significantly. Moreover, higher IgG concentrations were detected in the EtCHP18905 vaccinated chickens. Thus, EtCHP18905 might be a supplementary candidate, alongside other proteins that stimulate cellular immunity for the development of new vaccines to combat E. tenella infection in chickens.

\section{Conclusions}

In this study, EtCHP18905 was amplified, expressed and characterized. Its location on $\mathrm{Spz}$ and $\mathrm{Mrz}$ was determined. Anti-rEtCHP18905 antibodies could reduce the rate of Spz invasion. The results of animal immune protection assays indicated that vaccination with $\mathrm{rEtCHP} 18905$ was capable of eliciting both humoral immunity and cell-mediated immunity, providing moderate protective immunity against E. tenella. However, the exact roles of $E t \mathrm{CHP} 18905$ in coccidial infections require further investigation.

\section{Competing interest}

The authors declare that they have no competing interests.

Acknowledgements. We would like to thank all organisations that funded this work and all the teachers who cooperated in technical assistance. This research was supported by the National Natural Science Foundation of China (No. 31970420) and National Key R\&D Program of China (No. 2018YFD0500302) and the National Parasitic Resources Center (No. NPRC-2019-194-30).

\section{References}

1. Anderson L, Seilhamer J. 1997. A comparison of selected mRNA and protein abundances in human liver. Electrophoresis, 18(3-4), 533-537.

2. Blake DP. 2015. Eimeria genomics: Where are we now and where are we going? Veterinary Parasitology, 212(1-2), 68-74.

3. Burgess RR. 2009. Elution of proteins from gels. Methods in Enzymology, 463, 565-572.

4. Constantinoiu CC, Molloy JB, Jorgensen WK, Coleman GT. 2008. Antibody response against endogenous stages of an attenuated strain of Eimeria tenella. Veterinary Parasitology, 154(3-4), 193-204.

5. de Sousa Abreu R, Penalva LO, Marcotte EM, Vogel C. 2009. Global signatures of protein and mRNA expression levels. Molecular Biosystems, 5(12), 1512-1526.

6. Ding X, Lillehoj HS, Quiroz MA, Bevensee E, Lillehoj EP. 2004. Protective immunity against Eimeria acervulina following in ovo immunization with a recombinant subunit vaccine and cytokine genes. Infection and Immunity, 72(12), 69396944. 
7. Dong H, Wang Y, Han H, Li T, Zhao Q, Zhu S, Li L, Wu Y, Huang B. 2014. Identification and characterization of an Eimeria-conserved protein in Eimeria tenella. Parasitology Research, 113(2), 735-745.

8. Gebauer F, Hentze MW. 2004. Molecular mechanisms of translational control. Nature Reviews: Molecular Cell Biology, 5(10), 827-835.

9. Gordon HM, Whitlock HV. 1939. A new technique for counting nematode eggs in sheep faeces. Journal of the Council for Scientific and Industrial Research, 12, 50-52.

10. Gygi SP, Rochon Y, Franza BR, Aebersold R. 1999. Correlation between protein and mRNA abundance in yeast. Molecular and Cellular Biology, 19(3), 1720-1730.

11. Han H, Kong C, Dong H, Zhu S, Zhao Q, Zhai Q, Liang S, Li S, Yang S, Huang B. 2015. Molecular characterization and functional analysis of subunit 7 of eukaryotic initiation factor 3 from Eimeria tenella. Experimental Parasitology, 154, 118-126.

12. Hein H. 1971. Pathogenic effects of Eimeria necatrix in young chickens. Experimental Parasitology, 30(3), 321-330.

13. Hilleren P, Parker R. 1999. Mechanisms of mRNA surveillance in eukaryotes. Annual Review of Genetics, 33, 229-260.

14. Hoan TD, Zhang Z, Huang J, Yan R, Song X, Xu L, Li X. 2016. Identification and immunogenicity of microneme protein 2 (EbMIC2) of Eimeria brunetti. Experimental Parasitology, 162, 7-17.

15. Hong YH, Lillehoj HS, Lee SH, Dalloul RA, Lillehoj EP. 2006. Analysis of chicken cytokine and chemokine gene expression following Eimeria acervulina and Eimeria tenella infections. Veterinary Immunology and Immunopathology, 114(3-4), 209-223.

16. Huang J, Zhang Z, Li M, Song X, Yan R, Xu L, Li X. 2015. Immune protection of microneme 7 (EmMIC7) against Eimeria maxima challenge in chickens. Avian Pathology, 44(5), 392-400.

17. Jahn D, Matros A, Bakulina AY, Tiedemann J, Schubert U, Giersberg M, Haehnel S, Zoufal K, Mock HP, Kipriyanov SM. 2009. Model structure of the immunodominant surface antigen of Eimeria tenella identified as a target for sporozoite-neutralizing monoclonal antibody. Parasitology Research, 105(3), 655-668.

18. Jang SI, Lillehoj HS, Lee SH, Lee KW, Park MS, Cha SR, Lillehoj EP, Subramanian BM, Sriraman R, Srinivasan VA. 2010. Eimeria maxima recombinant Gam82 gametocyte antigen vaccine protects against coccidiosis and augments humoral and cell-mediated immunity. Vaccine, 28(17), 2980-2985.

19. Jiang L, Lin J, Han H, Zhao Q, Dong H, Zhu S, Huang B. 2012. Identification and partial characterization of a serine protease inhibitor (serpin) of Eimeria tenella. Parasitology Research, $110(2), 865-874$.

20. Johnson J, Reid WM. 1970. Anticoccidial drugs: lesion scoring techniques in battery and floor-pen experiments with chickens. Experimental Parasitology, 28(1), 30-36.

21. Kehrl JH, Roberts AB, Wakefield LM, Jakowlew S, Sporn MB, Fauci AS. 1986. Transforming growth factor beta is an important immunomodulatory protein for human B lymphocytes. Journal of Immunology, 137(12), 3855-3860.

22. Lee KW, Lillehoj HS, Jang SI, Lee SH, Bautista DA, Donald Ritter G, Lillehoj EP, Siragusa GR. 2013. Comparison of live Eimeria vaccination with in-feed salinomycin on growth and immune status in broiler chickens. Research in Veterinary Science, 95(1), 110-114.

23. Lillehoj HS, Min W, Dalloul RA. 2004. Recent progress on the cytokine regulation of intestinal immune responses to Eimeria. Poultry Science, 83(4), 611-623.

24. Lillehoj HS, Ding X, Quiroz MA, Bevensee E, Lillehoj EP. 2005. Resistance to intestinal coccidiosis following DNA immunization with the cloned 3-1E Eimeria gene plus IL-2, IL-15, and IFN-gamma. Avian Diseases, 49(1), 112-117.
25. Lin RQ, Lillehoj HS, Lee SK, Oh S, Panebra A, Lillehoj EP. 2017. Vaccination with Eimeria tenella elongation factor-1alpha recombinant protein induces protective immunity against E. tenella and E. maxima infections. Veterinary Parasitology, 243, 79-84.

26. Liu T, Huang J, Li Y, Ehsan M, Wang S, Zhou Z, Song X, Yan R, Xu L, Li X. 2018. Molecular characterisation and the protective immunity evaluation of Eimeria maxima surface antigen gene. Parasites \& Vectors, 11(1), 325.

27. Livak KJ, Schmittgen TD. 2001. Analysis of relative gene expression data using real-time quantitative PCR and the 2(-Delta Delta C(T)) method. Methods, 25(4), 402-408.

28. Miska KB, Fetterer RH, Barfield RC. 2004. Analysis of transcripts expressed by Eimeria tenella oocysts using subtractive hybridization methods. Journal of Parasitology, 90(6), $1245-1252$.

29. Pradet-Balade B, Boulmé F, Beug H, Müllner EW, Garcia-Sanz JA. 2001. Translation control: bridging the gap between genomics and proteomics? Trends in Biochemical Sciences, 26(4), 225-229.

30. Reid AJ, Blake DP, Ansari HR, Billington K, Browne HP, Bryant J, Dunn M, Hung SS, Kawahara F, Miranda-Saavedra D, Malas TB, Mourier T, Naghra H, Nair M, Otto TD, Rawlings ND, Rivailler P, Sanchez-Flores A, Sanders M, Subramaniam C, Tay YL, Woo Y, Wu X, Barrell B, Dear PH, Doerig C, Gruber A, Ivens AC, Parkinson J, Rajandream MA, Shirley MW, Wan KL, Berriman M, Tomley FM, Pain A. 2014. Genomic analysis of the causative agents of coccidiosis in domestic chickens. Genome Research, 24(10), 1676-1685.

31. Rose MEMA. 1983. Antibodies to coccidia detection by the enzyme-linked immunosorbent assay (ELISA). Parasite Immunology, 5(5), 479-489.

32. Rothwell L, Young JR, Zoorob R, Whittaker CA, Hesketh P, Archer A, Smith AL, Kaiser P. 2004. Cloning and characterization of chicken IL-10 and its role in the immune response to Eimeria maxima. Journal of Immunology, 173(4), 2675-2682.

33. Sharma S, Azmi S, Iqbal A, Nasirudullah N, Mushtaq I. 2015. Pathomorphological alterations associated with chicken coccidiosis in Jammu division of India. Journal of Parasitic Diseases, 39(2), 147-151.

34. Shirley MW, Lillehoj HS. 2012. The long view: a selective review of 40 years of coccidiosis research. Avian Pathology, 41(2), 111-121.

35. Shirley MW, Eckert J, Braun R. 1995. Eimeria species and strains of chickens, in Biotechnology - Guidelines on Techniques in Coccidiosis Research, 9-10.

36. Smith NC, Wallach M, Miller CM, Morgenstern R, Braun R, Eckert J. 1994. Maternal transmission of immunity to Eimeria maxima: enzyme-linked immunosorbent assay analysis of protective antibodies induced by infection. Infection and Immunity, 62(4), 1348-1357.

37. Song H, Song X, Xu L, Yan R, Shah MA, Li X. 2010. Changes of cytokines and IgG antibody in chickens vaccinated with DNA vaccines encoding Eimeria acervulina lactate dehydrogenase. Veterinary Parasitology, 173(3-4), 219-227.

38. Song H, Yan R, Xu L, Song X, Shah MA, Zhu H, Li X. 2010. Efficacy of DNA vaccines carrying Eimeria acervulina lactate dehydrogenase antigen gene against coccidiosis. Experimental Parasitology, 126(2), 224-231.

39. Subramanian BM, Sriraman R, Rao NH, Raghul J, Thiagarajan D, Srinivasan VA. 2008. Cloning, expression and evaluation of the efficacy of a recombinant Eimeria tenella sporozoite antigen in birds. Vaccine, 26(27-28), 3489-3496.

40. Tomley F. 1997. Techniques for isolation and characterization of apical organelles from Eimeria tenella sporozoites. METHODS: A Companion to Methods in Enzymology, 13, 5. 
41. Willsie SK, Herndon BL, Miller L, Dew M. 1996. Soluble versus cell-bound CD4, CD8 from bronchoalveolar lavage: correlation with pulmonary diagnoses in human immunodeficiency virus-infected individuals. Journal of Leukocyte Biology, 59(6), 813-816.

42. Wu Z, Hu T, Rothwell L, Vervelde L, Kaiser P, Boulton K, Nolan MJ, Tomley FM, Blake DP, Hume DA. 2016. Analysis of the function of IL-10 in chickens using specific neutralising antibodies and a sensitive capture ELISA. Developmental and Comparative Immunology, 63, 206-212.

43. Xu Q, Song X, Xu L, Yan R, Shah MA, Li X. 2008. Vaccination of chickens with a chimeric DNA vaccine encoding Eimeria tenella TA4 and chicken IL-2 induces protective immunity against coccidiosis. Veterinary Parasitology, 156(3-4), 319-323.

44. Yan M, Cui X, Zhao Q, Zhu S, Huang B, Wang L, Zhao H, Liu G, Li Z, Han H, Dong H. 2018. Molecular characterization and protective efficacy of the microneme 2 protein from Eimeria tenella. Parasite, 25, 60.
45. Yun CH, Lillehoj HS, Lillehoj EP. 2000. Intestinal immune responses to coccidiosis. Developmental and Comparative Immunology, 24(2-3), 303-324.

46. Zajkowska J, Hermanowska-Szpakowicz T, Swierzbinska R. 2001. Concentration of soluble CD4, CD8 and CD25 receptors in early localized and early disseminated Lyme borreliosis. Infection, 29(2), 71-74.

47. Zhai Q, Huang B, Dong H, Zhao Q, Zhu S, Liang S, Li S, Yang S, Han H. 2016. Molecular characterization and immune protection of a new conserved hypothetical protein of Eimeria tenella. PLoS One, 11(6), e0157678.

48. Zhao H, Zhao Q, Zhu S, Huang B, Lv L, Liu G, Li Z, Wang L, Dong H, Han H. 2020. Molecular characterization and immune protection of an AN1-like zinc finger protein of Eimeria tenella. Parasitology Research, 119(2), 623-635.

49. Zhu H, Xu L, Yan R, Song X, Tang F, Wang S, Li X. 2012. Identification and characterization of a cDNA clone-encoding antigen of Eimeria acervulina. Parasitology, 139(13), 1711-1719.

Cite this article as: Zhao H, Zhu S, Zhao Q, Huang B, Liu G, Li Z, Wang L, Dong H \& Han H. 2021. Molecular characterization and protective efficacy of a new conserved hypothetical protein of Eimeria tenella. Parasite 28, 40.

\section{-0 PARASTE}

An international open-access, peer-reviewed, online journal publishing high quality papers on all aspects of human and animal parasitology

Reviews, articles and short notes may be submitted. Fields include, but are not limited to: general, medical and veterinary parasitology; morphology, including ultrastructure; parasite systematics, including entomology, acarology, helminthology and protistology, and molecular analyses; molecular biology and biochemistry; immunology of parasitic diseases; host-parasite relationships; ecology and life history of parasites; epidemiology; therapeutics; new diagnostic tools.

All papers in Parasite are published in English. Manuscripts should have a broad interest and must not have been published or submitted elsewhere. No limit is imposed on the length of manuscripts.

Parasite (open-access) continues Parasite (print and online editions, 1994-2012) and Annales de Parasitologie Humaine et Comparée (1923-1993) and is the official journal of the Société Française de Parasitologie. 